\title{
Screening of anticancer drugs as potential candidates to target COVID-19 disease
}

\author{
Gayatri S Gurjar $^{1^{*}}$ \\ ${ }^{1}$ Department of Biotechnology, Fergusson College (Autonomous), Pune, Maharashtra, India-411004 \\ *Corresponding author:gayatri.gurjar@fergusson.edu
}

\section{Abstract:}

COVID-19, a disease which emerged in year 2019 has currently become a matter of global concern. This disease has not only affected thousands of lives all around a world, but has also severely impacted world economy. The need of the hour now is to develop strategies to combat this disease. Several researchers are contributing towards understanding this virus, developing a vaccine against it or deciphering new therapies to fight it. This current study was focused to evaluate the ability of anticancer agents to inhibit COVID-19 by targeting its enzymes like protease and endoribonuclease or its structural proteins like spike and post fusion proteins. The study details out several promising anticancer drugs which can be potential inhibitors of COVID-19 disease. These anticancer agents however need to be evaluated further by more stringent computational tool and wet lab screening, so that they can help in curbing this disease. This is the first report wherein anticancer drugs are predicted to be viable remedy against COVID-19.

Key words: Anticancer drugs, COVID-19, molecular docking based prediction, therapy alternatives 


\section{Introduction}

The SARS-CoV-2, a rampant virus emerged first in December 2019 in Wuhan, China and then spread rapidly worldwide. Some preliminary work done so far has suggested the use of antimalarial drug chloroquine to treat of coronavirus disease 2019 (COVID-19) infections (Colson et al. 2020). Chloroquine phosphate has been recommended to treat COVID-19 associated pneumonia in the study. Another study performed by Liu and Wang (2020) with drugs such as nelfinavir, pitavastatin, perampanel, and praziquantel indicated nelfinavir as the best potential inhibitor against COVID-19. Further research by another group of scientists, based on clinical trials suggested that hydroxychloroquine along with azithromycin can be an efficient strategy in the treatment of the COVID-19 (Shrivastava et al. 2020). Several other antivirals have also been tested such as arbidol, remdesivir, and favipiravir for their efficacy and safety. These medications are currently undergoing clinical studies against treatment of COVID-19 and some promising results have been achieved so far (Dong et al. 2020).

However, there is a need to develop new diagnostics, vaccines and therapeutics against this disease which has gained global concern. One of the major hindrances to tackle this virus is the possibility of it being mutated rendering development of vaccines ineffective against it. Very recently, in January 2020 a new mutation in the novel coronavirus SARS-CoV-2, has been traced by researchers from Taiwan and Australia (Yong et al. 2020). This mutation in the virus may lead to a weaker receptor binding capability with human cells (ACE2), due to a change in its spike protein. Hence there is an urgent need to develop and identify new antivirals or screen the existing ones against COVID-19. This will help in curbing the expanding spread of this virus. 
Research has shown a strong positive correlation between cancer and some viruses (Roner et al. 2008). Viruses that contain DNA as the genetic information induce host cell division to initiate their own replication. This holds true for some retroviruses too for which an intact nuclear envelope is a barrier and does not permit the integration of the provirus into the host genome. These viruses induce altered host cell division compared to the way in which these cells would divide normally. Cancers too can modify the cellular machinery to replicate, establish and expand themselves. These modifications to cellular machinery are common to both viral infections and tumor cell growth. Hence it would be reasonable to screen for drugs that can inhibit unwanted host cell growth and also viral replication in the host system. In year 1977, it was noted by Reeves and others that the antitumor drug Gleevec was capable of inhibiting Vaccinia virus (Roner et al. 2008). In studies conducted with Tilorone and Cisplatin, both these anticancer agents were found to be effective against both DNA as well as RNA viruses (Roner et al. 2008). Further, in studies conducted by Bekerman et al 2017, it was validated that Sunitinib- and Erlotinib-mediated inhibition of kinase regulation activity was an important mechanism of antiviral action against hepatitis C virus (HCV) infection.

Recent experimental and clinical data indicates that molecules targeting single protein may prove to be insufficient to overcome COVID-19. Hence an effective strategy would be to search for drugs that can target multiple key proteins (Joshi et al 2020). The main protease $\left(M^{\text {pro }}\right) /$ chymotrypsin like protease (3CLpro) from COVID-19, has a vital role in polyprotein processing as well as viral maturation and hence it represents itself as a potential target for the inhibition of CoV replication. This protease (6Y2E) has been analyzed previously for drug discovery purposes and it also indicates very low similarity with human proteases (Joshi et al 2020). In the current study 6Y2E along with $20 P 9$ and 6LU7 (as used and suggested by Yoshino et al 2020 in their study) $M^{\text {pro }}$ structures were downloaded 
from the Protein Data Bank (PDB). The SARS-CoV spike (S) protein is yet another promising target for vaccine and therapeutic development. It is composed of two subunits; the S1 subunit that contains a receptor-binding domain which engages with the host cell receptor angiotensin-converting enzyme 2 (ACE2) along with the S2 subunit that mediates fusion between the viral and host cell membranes (Du et al 2009).

In a recent study by Abbasi et al 2020, it was revealed that glycosylated spike (S) protein of 2019-nCov, a significant contributor to 2019- nCov infection in human body binds with host cells' receptors through the subunit (S1). On the other hand S2 subunit (post fusion core of 2019-nCov) is important for fusion of 2019-nCov with host cell membrane and subsequent inoculation of its genome in to the host cell. Both membrane fusion and receptor binding are critical in COVID-19 spread. Thus blocking the active sites of viral spike protein and post fusion core protein may reduce COVID-19 infections in human; and they (2GHV, $6 \mathrm{LXT})$ seem to be an ideal target for study. In studies conducted by Joshi and Poduri 2020, NSP15 endoribonuclease from SARS CoV-2 (6VWW) was revealed as a potential target protein. NSP15 is a RNA possessing RNA uridylate-specific endoribonuclease (NendoU). RNA uridylate-specific endoribonuclease is widespread in its occurence, including viruses and eukaryotic cells. In viruses these enzymes are specifically conserved in coronaviruses, arteriviruses, and toroviruses. Also, the SARS-CoV-2 NendoU oligomer shares high similarity with those of SARS-CoV, HCoV-229E, and MERS-CoV enzymes.

This paper describes the preliminary screening of several anticancer drugs using in silico approach against various COVID-19 protein targets. Using this information as a foundation, these promising anticancer candidates can further be scrutinized through computational analysis and wet lab validation, further to be established as viable therapies against COVID-19 disease. The current work 
suggests a strong interaction between several anticancer drugs routinely used for treatment of various types of cancer and potential targets of COVID-19.

\section{Materials and methods:}

Molecular Docking: An automated in silico molecular-docking approach that uses SwissDock web server (Grosdidier et al 2011), based on the docking algorithm EADock ESS was employed in the current study. It is a free of cost software available online and is powered by research group of Swiss Institute of Bioinformatics. The potential targets used for analysis included the main protease of corona virus (6Y2E, $2 \mathrm{OP9}$ and 6LU7) as used in previous studies. Along with these, viral spike protein and post fusion core protein (2GHV, 6LXT) and NSP15 endoribonuclease (6VWW) were also used. These target proteins were retrieved from the RCSB protein data bank (https://www.rcsb.org/). The anticancer drug ligand structures that were used as input for molecular docking were retrieved from PubChem database (https://pubchem.ncbi.nlm.nih.gov/). PubChem is a database of chemical substances and depicts their biological activities and is linked with substance, compound, and bioassay databases. SwissDock allows for blind docking and it predicts all potential binding sites on a target protein through EADock ESS algorithm. The database is also equipped with a database of proteins and ligand structures. EADock ESS generates several binding modes of a ligand and the most favorable binding modes are clustered. Each cluster represents all available conformations of a ligand at the given location on the protein along with the binding pocket of the target protein. It also provides an output/predictions file. Molecular docking was performed using the 'Accurate' parameter option in SwissDock online tool. 
Visualization of protein-ligand interactions: UCSF Chimera (Pettersen et al 2004), which is a noncommercial free web resource developed by University of California San Francisco, was used to determine protein-ligand interactions. The amino acid residues that displayed interactions with the ligands were analyzed and Hydrogen $(H)$ bonds along with their distances with ligand were determined. Further hydrophobicity of some target proteins was observed during its interaction with ligands.

Determination of ADMET properties: We also retrieved lipophilicity (log P) and aqueous solubility (log S) data from Drugbank (https://www.drugbank.ca/) which is a unique bioinformatics and cheminformatics resource with detailed drug data and comprehensive drug target information. Further, the drug type and its status followed by its uses, properties and the structures were also recorded.

\section{Results and discussion:}

In this study, several anticancer drugs suggested routinely for the treatment of several types of cancers and tumors were chosen as potential ligands to target COVID-19 proteins. Table 1 enlists the anticancer drugs chosen for molecular docking studies against six protein targets of SARS COV. As mentioned in the introduction, structures of major protease of the SARS Coronavirus $(2 \mathrm{OP}, 6 \mathrm{Y} 2 \mathrm{E}$ and 6LU7-in complex with inhibitor) were chosen based on prior literature survey. Also, 2GHV- the SARS spike protein receptor binding domain, 6LXT- post fusion core of 2019-nCoV S2 subunit and 6VWWNSP15 endoribonuclease from SARS CoV-2, were considered for analysis.

Molecular docking calculations were performed as blind, which ensured that the entire target protein surface was covered, and docking was not specifically accomplished with any particular region 
of the protein. The output clusters were generated after each docking step and ranked according to the full fitness (FF) score by the SwissDock algorithm. A greater negative FF score suggested a more favorable binding mode between ligand and receptor with a better fit. Primary analysis was conducted with ligands (anticancer drugs) listed in table 1 with four protein targets (2OP9, 6Y2E, 6LU7 and 2GHV). Only those ligands which showed a $\Delta \mathrm{G}$ score of less than -9 (detailed in red font color in table 1) with at least 1 target protein were selected for further analysis.

\begin{tabular}{|c|c|c|c|c|}
\hline Drug/target & $\begin{array}{l}\text { 20P9 Major Protease of } \\
\text { the SARS Coronavirus }\end{array}$ & $\begin{array}{l}\text { 2GHV Crystal structure of } \\
\text { SARS spike protein } \\
\text { receptor binding domain }\end{array}$ & $\begin{array}{l}\text { 6Y2E Crystal structure of the free } \\
\text { enzyme of the SARS-CoV-2 (2019- } \\
\text { nCoV) main protease }\end{array}$ & $\begin{array}{l}\text { 6LU7 The crystal structure of } \\
\text { COVID-19 main protease in } \\
\text { complex with an inhibitor N3 }\end{array}$ \\
\hline $\begin{array}{l}\text { Hydroxychloroquine } \\
\text { (control) }\end{array}$ & -8.05 & -8.86 & -8.8 & -8.22 \\
\hline Valrubicin & -10.34 & -9 & -9.5 & -8.7 \\
\hline Vinorelbine & -9.4 & -9.17 & -9.09 & -8.7 \\
\hline Methotrexate & -10.4 & -9.62 & -9.6 & -8.96 \\
\hline Docetaxel & -11.11 & -8.82 & -8.9 & -8.4 \\
\hline Tamoxifen & -8.6 & -8.09 & -9.1 & -9.07 \\
\hline Aderbasib & -8.72 & -8.43 & -8.58 & -8.14 \\
\hline Idarubicin & -8.9 & -7.7 & -8.9 & -8.81 \\
\hline Oxaliplatin & -8 & -9.4 & Poor & -9.32 \\
\hline Tilorone & -8.98 & -7.8 & -9.7 & -8.9 \\
\hline Erlotinib & -8.3 & -8.04 & -8.6 & -7.5 \\
\hline Rucaparib & -8.02 & -7.9 & -8.6 & -8.32 \\
\hline GW5074 & -9.46 & -9.8 & -8.65 & -9.46 \\
\hline Sertraline & -7.91 & -8.1 & -8.5 & -8.02 \\
\hline Olomoucin & -8.09 & -7.8 & -8.01 & -7.6 \\
\hline Tegafur & Poor & poor & Poor & poor \\
\hline Podophyllotoxin & -8.3 & poor & -8.5 & -7.56 \\
\hline Wortmannin & -8.09 & -7.79 & -8.3 & -7.3 \\
\hline Gefitinib & -8.93 & -8.46 & -8.4 & -7.58 \\
\hline LY294002 & -7.7 & poor & poor & poor \\
\hline Temozolomide & poor & poor & Poor & poor \\
\hline Imipramine & not determined & not determined & -8.3 & not determined \\
\hline Dacarbazine & Poor & poor & Poor & not determined \\
\hline Procarbazine & Poor & poor & Poor & not determined \\
\hline Prednisolone & -8 & -7.9 & -7.8 & not determined \\
\hline
\end{tabular}

Hydroxychloroquine was chosen as a positive control in the analysis for molecular docking, since it is currently being scrutinized and considered as one of the remedies for COVID-19. A $\Delta \mathrm{G}$ score of more than -7.5 was considered as poor and such candidates were not chosen for further analysis. 
Through this exercise four promising anticancer drugs were chosen based on their lowest $\Delta \mathrm{G}$ scoresValrubicin, Vinorelbine, Methotrexate and Docetaxel. Out of these ligands Docetaxel, Valrubicin and Methotrexate showed $\Delta \mathrm{G}$ score of $-11.11,-10.34$ and -10.34 with 2OP9 (main protease) target protein. These four anticancer candidate molecules were further used for molecular docking with two more target proteins namely- 6LXT (post fusion core of 2019-nCoV S2 subunit) and 6VWW (NSP15 endoribonuclease from SARS CoV-2). Table 2 details out the docking parameters such as $\Delta \mathrm{G}$ scores, FF values of these four candidate ligands, along with the amino acids (residues) found in the active site pockets of respective target proteins. The results of molecular docking are displayed in Figs. 1-5.

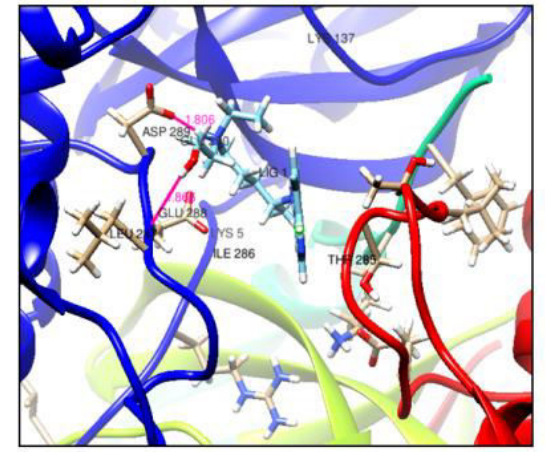

2OP9_HYDROXYCHLOROQUINE

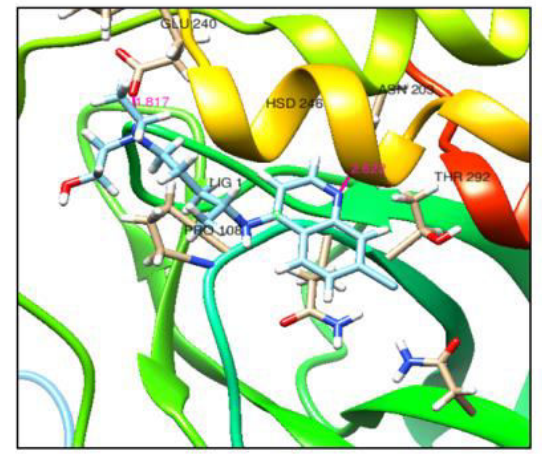

6Y2E_HYDROXYCHLOROQUINE

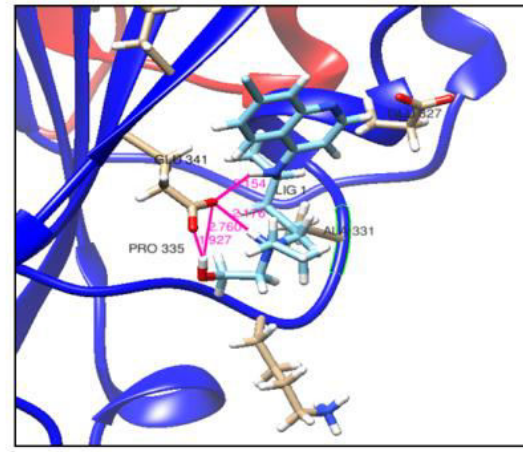

2GHV_HYDROXYCHLOROQUINE

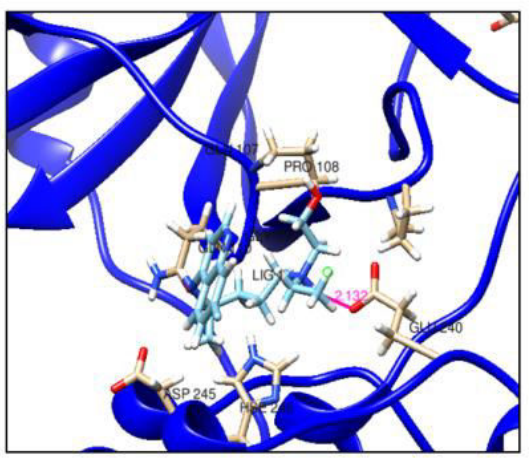

6LU7_HYDROXYCHLOROQUINE

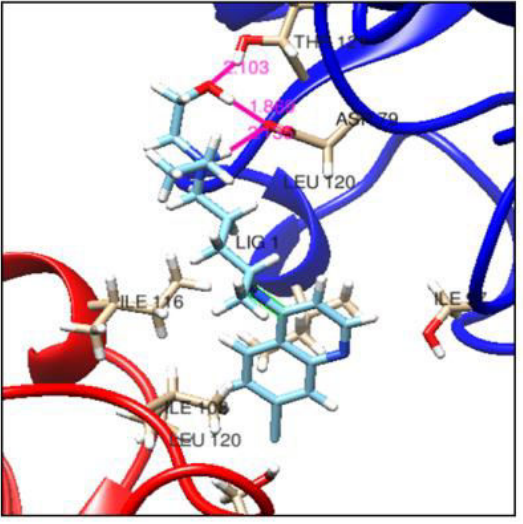

6VWW_HYDROXYCHLOROQUINE

Fig 1. Molecular docking results of Hydroxychloroquine with target proteins 2OP9, 2GHV, 6Y2E, 6LU7, and 6VWW 


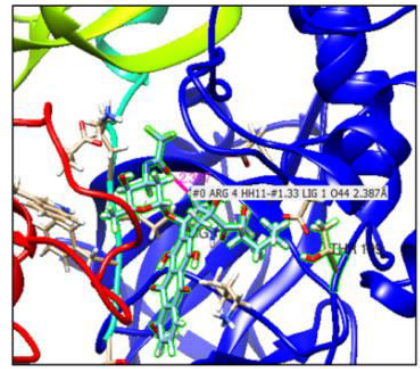

2OP9_VALRUBICIN

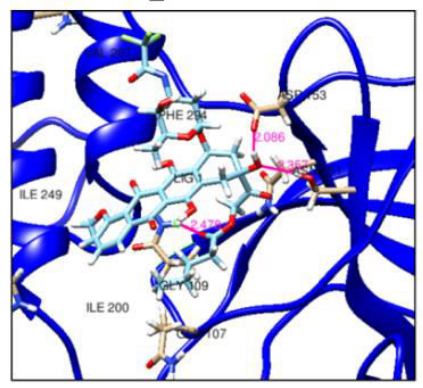

$6 L U 7$ VALRUBICIN

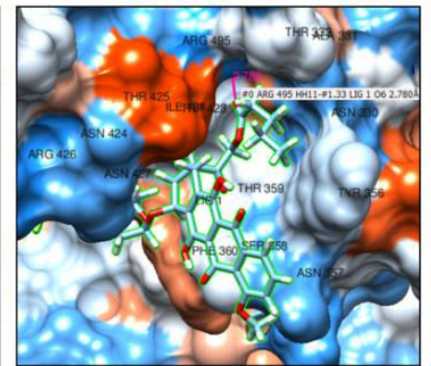

2GHV_VALRUBICIN

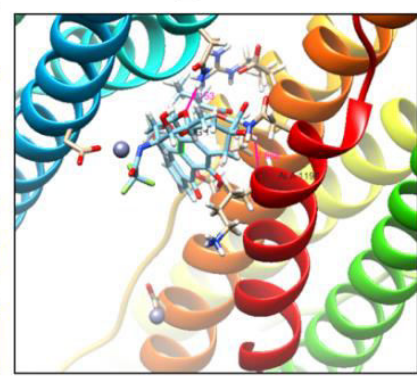

6LXT_VALRUBICIN

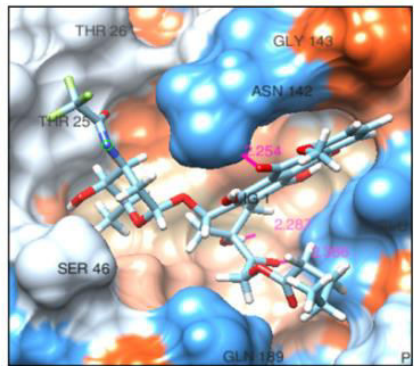

6Y2E_VALRUBICIN

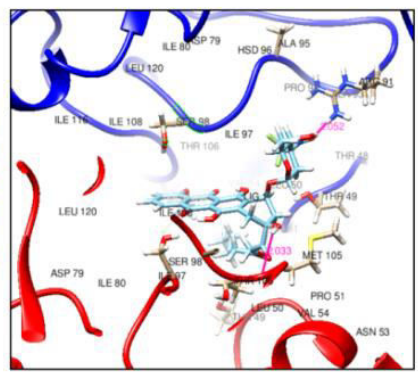

6VWW_VALRUBICIN

Fig 2. Molecular docking results of Valrubicin with target proteins 2OP9, 2GHV, 6Y2E, 6LU7, 6LXT and 6VWW

The results of docking analyses showed that Methotrexate formed maximum number of (six) $\mathrm{H}$ bonds with residues (GLN, ARG and ALA) in the target protein 2GHV (fig 3).

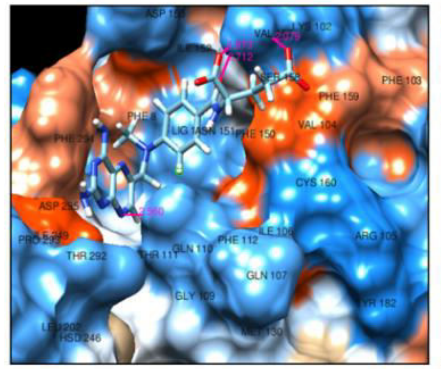

6OP9_METHOTREXATE

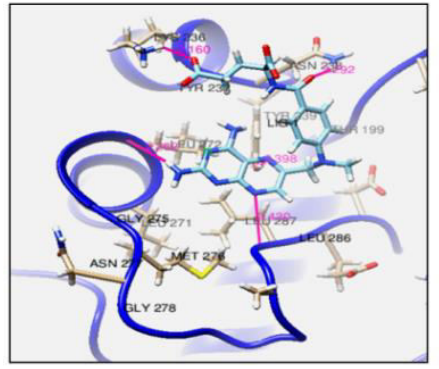

6LU7_METHOTREXATE

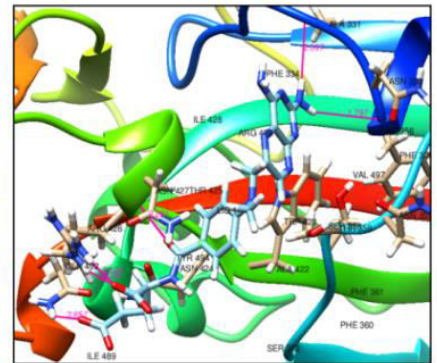

2GHV_METHOTREXATE

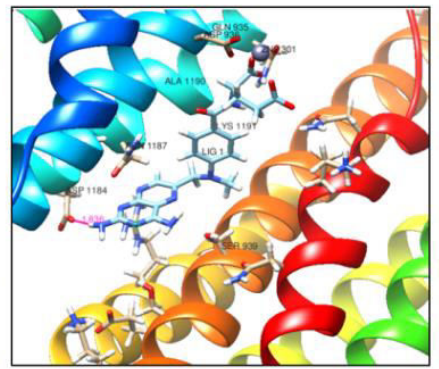

6LXT_METHOTREXATE

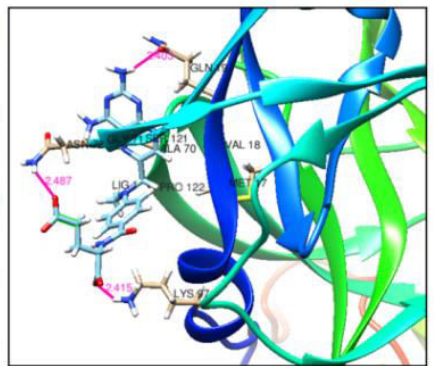

6Y2E_METHOTREXATE

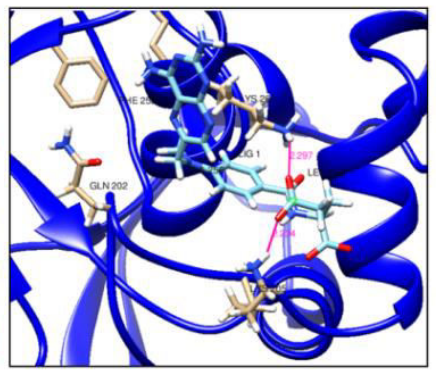

6VWW_METHOTREXATE

Fig 3. Molecular docking results of Methotrexate with target proteins 2OP9, 2GHV, 6Y2E, 6LU7, 6LXT and 6VWW 
On the other hand, Vinorelbine formed only $1 \mathrm{H}$ bond with respective residues (fig 4) across all six target proteins (table 2).

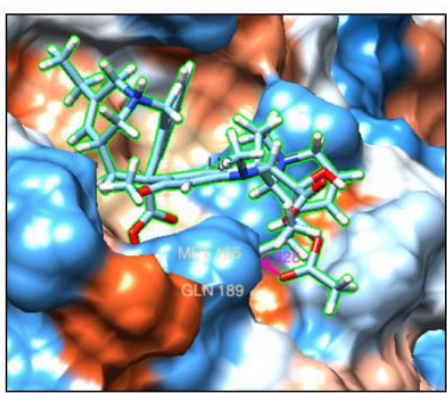

6OP9_VINORELBINE

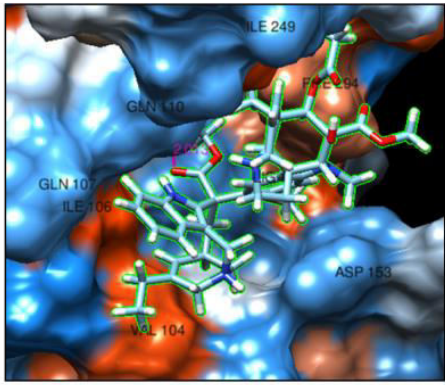

6LU7_VINORELBINE

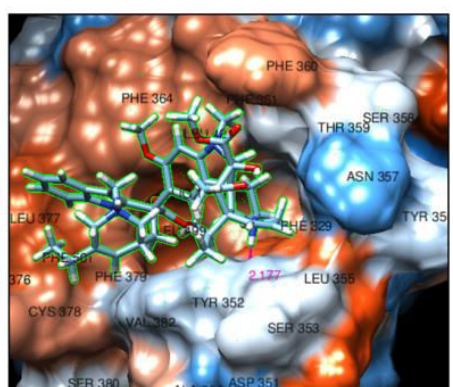

2GHV VINORELBINE

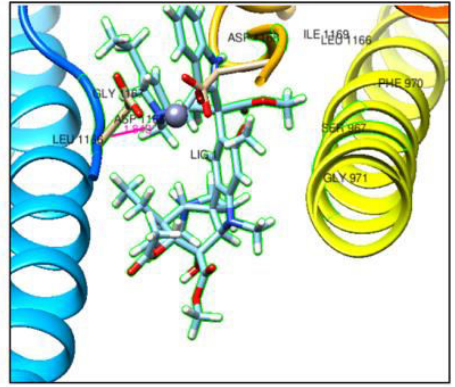

6LXT_VINORELBINE

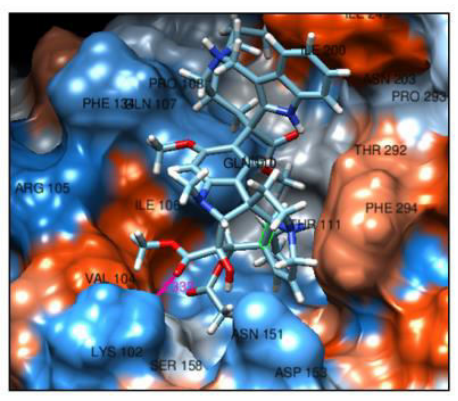

6Y2E_VINORELBINE

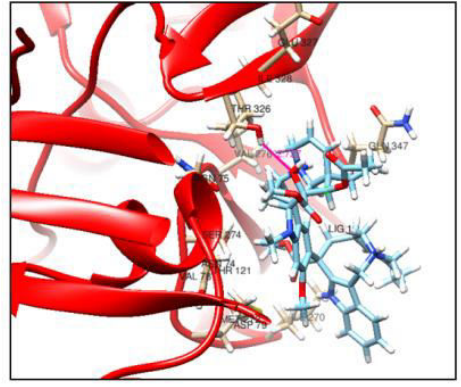

6VWW_VINORELBINE

Fig 4. Molecular docking results of Vinorelbine with target proteins 2OP9, 2GHV, 6Y2E, 6LU7, 6LXT and 6VWW

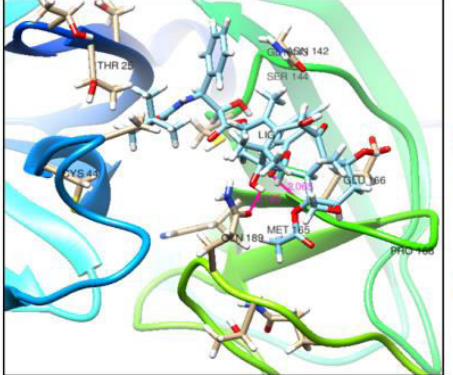

2OP9_DOCETAXEL

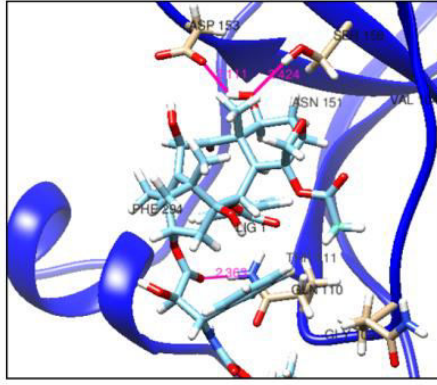

6LU7_DOCETAXEL

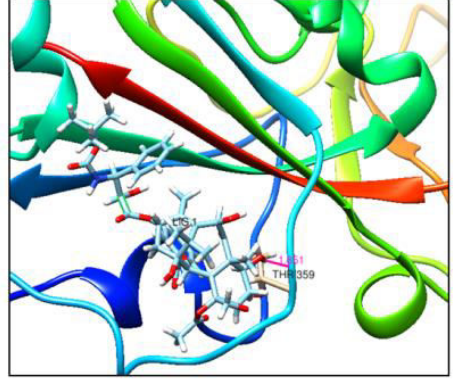

2GHV_DOCETAXEL

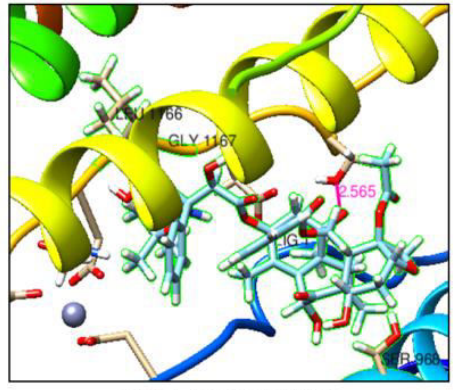

6LXT_DOCETAXEL

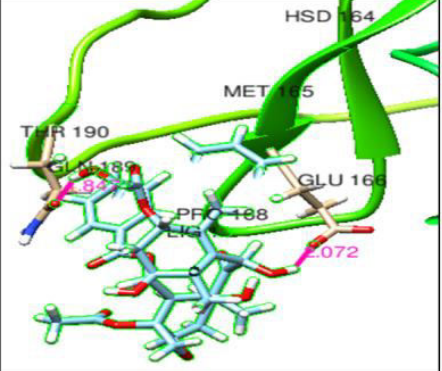

6Y2E DOCETAXEL

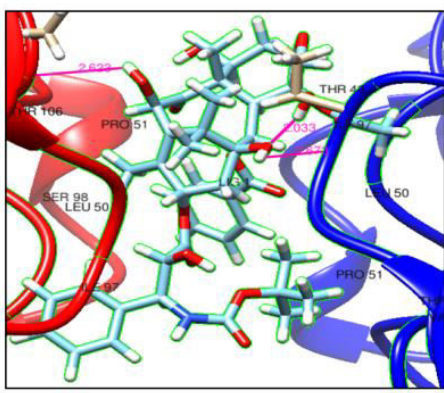

6VWW_DOCETAXEL

Fig 5. Molecular docking results of Vinorelbine with target proteins 2OP9, 2GHV, 6Y2E, 6LU7, 6LXT and 6VWW 
Table 2. Details of binding affinity, Fullfitness (FF) values; and residue and bond length of selected anti cancer drugs that could act as possible COVID-19 inhibitors

\begin{tabular}{|c|c|c|c|c|c|c|}
\hline Drug molecule/ Target protein & $\begin{array}{l}\text { 2OP9 (Major Protease of the } \\
\text { SARS Coronavirus) }\end{array}$ & $\begin{array}{l}\text { 2GHV (Crystal structure of } \\
\text { SARS spike protein receptor } \\
\text { binding domain) }\end{array}$ & $\begin{array}{l}\text { 6Y2E (Crystal structure of the } \\
\text { free enzyme of the SARS-CoV- } \\
2 \text { (2019-nCoV) main protease) }\end{array}$ & $\begin{array}{l}\text { 6LU7 (The crystal structure of } \\
\text { COVID-19 main protease in } \\
\text { complex with an inhibitor N3) }\end{array}$ & $\begin{array}{l}\text { 6LXT (Structure of post fusion } \\
\text { core of 2019-nCoV S2 subunit) }\end{array}$ & $\begin{array}{l}\text { 6VWW (Crystal Structure of } \\
\text { NSP15 Endoribonuclease from } \\
\text { SARS CoV-2) }\end{array}$ \\
\hline Hydroxychloroquine ( $\Delta \mathrm{G}$ values) & -8.05 & -8.86 & -8.8 & -8 & -8.56 & -8.52 \\
\hline Fullfitness & $(-2366.814)$ & $(-1640.5045)$ & $(-1161.1492)$ & $(-1235.8539$ & $(-5317.103)$ & $(-3757.0002)$ \\
\hline Residue, $\mathrm{H}$ bond lengths & Leu $287,1.866 \mathrm{~A}$ & GLU $341,1.927 \mathrm{~A}$ & ASN 203, 2.622 A & GLU 240, $2.132 \mathrm{~A}$ & no $\mathrm{H}$ bonds found & THR 121, 2.103 A \\
\hline Residue, $\mathrm{H}$ bond lengths & ASP $289,1.806 \mathrm{~A}$ & GLU $341,2.760 \mathrm{~A}$ & GLU 240, 1.817 A & & & ASP $79,1.869 \mathrm{~A}$ \\
\hline Residue, $\mathrm{H}$ bond lengths & & GLU $341,2.176 \mathrm{~A}$ & & & & ASP 79, $2.135 \mathrm{~A}$ \\
\hline Residue, $\mathrm{H}$ bond lengths & & GLU 341, 2.154 A & & & & \\
\hline Valrubicin ( $\Delta \mathrm{G}$ values) & -10.34 & -9 & -9.5 & -8.26 & -11.54 & -9.767 \\
\hline Fullfitness & $(-2279.792)$ & $(-1550.521)$ & $(-1080.8147)$ & $(-1156.0625)$ & $(-5247.0884)$ & $(-3670.122)$ \\
\hline Residue, $\mathrm{H}$ bond lengths & ARG 4, 2.387 A & ARG 495, $2.78 \mathrm{~A}$ & ASN $142,2.254 \mathrm{~A}$ & GLN 110, $2.478 \mathrm{~A}$ & ALA $1190,1.988 \mathrm{~A}$ & ARG $91,2.052 \mathrm{~A}$ \\
\hline Residue, $\mathrm{H}$ bond lengths & & & HSD 164, $2.287 \mathrm{~A}$ & ASP $153,2.086 \mathrm{~A}$ & ASN $1194,2.153 \mathrm{~A}$ & MET $105,2.033 \mathrm{~A}$ \\
\hline Residue, $\mathrm{H}$ bond lengths & & & GLU $166,2.386 \mathrm{~A}$ & SER $158,2.357 \mathrm{~A}$ & & \\
\hline Vinorelbine ( $\Delta \mathrm{G}$ values) & -10.25 & -9.17 & -9.09 & -8.7 & -8.92 & -9.79 \\
\hline Fullfitness & $(-1232.4712)$ & $(-735.10657)$ & $(-1036.124)$ & $(-1169.5951)$ & $(-5214.718)$ & $(-3664.6846)$ \\
\hline Residue, $\mathrm{H}$ bond lengths & GLN 189, $2.328 \mathrm{~A}$ & 2.177 A, TYR 352 & LYS $102,2.333 \mathrm{~A}$ & GLN 110, $2.013 \mathrm{~A}$ & ASP $1165,1.843 \mathrm{~A}$ & THR $326,2.727 \mathrm{~A}$ \\
\hline Methotrexate ( $\Delta \mathrm{G}$ values) & -10.4 & -9.86 & -9.67 & -8.96 & -13.74 & -10.41 \\
\hline Fullfitness & $(-1301.8118)$ & $(-841.4199)$ & $(-1202.7239)$ & $(-1285.3126)$ & $(-5351.1733)$ & $(-3792.8545)$ \\
\hline Residue, $\mathrm{H}$ bond lengths & GLN $110,2.560$ & GLN 492, $2.657 \mathrm{~A}$ & LYS $97,2.415 \mathrm{~A}$ & ASN 238, 2.292 A & ASP $1184,1.836 \mathrm{~A}$ & LYS $205,2.234 \mathrm{~A}$ \\
\hline Residue, $\mathrm{H}$ bond lengths & LYS $102,1.973 \mathrm{~A}$ & ARG $426,2.032 \mathrm{~A}$ & ASN $72,2.487 \mathrm{~A}$ & ASN $236,2.160 \mathrm{~A}$ & & LYS $260,2.297 \mathrm{~A}$ \\
\hline Residue, $\mathrm{H}$ bond lengths & LYS $102,2.079 \mathrm{~A}$ & ARG 426, 2.121 A & GLN 19, $2.403 \mathrm{~A}$ & LEU 272, $2.262 \mathrm{~A}$ & & \\
\hline Residue, $\mathrm{H}$ bond lengths & LYS $102,2.712 \mathrm{~A}$ & ARG $4262.281 \mathrm{~A}$ & & LEU $287,2.430 \mathrm{~A}$ & & \\
\hline Residue, $\mathrm{H}$ bond lengths & & ALA 331, $2.097 \mathrm{~A}$ & & TYR 239, $2.398 \mathrm{~A}$ & & \\
\hline Residue, $\mathrm{H}$ bond lengths & & PHE 329, 1.797 & & & & \\
\hline Docetaxel ( $\Delta \mathrm{G}$ values) & -11.11 & -8.74 & -8.9 & -8.4 & -9.21 & -8.96 \\
\hline Fullfitness & $(-1063.9298)$ & $(-596.4797)$ & $(-944.01355)$ & $(-1028.9792)$ & $(-5110.8286)$ & $(-3534.9355)$ \\
\hline Residue, $\mathrm{H}$ bond lengths & GLU 166, $2.065 \mathrm{~A}$ & THR $359,1.851 \mathrm{~A}$ & GLU $166,2.072 \mathrm{~A}$ & GLN 110, $2.363 \mathrm{~A}$ & SER $1170,2.565 \mathrm{~A}$ & MET $105,2.623 \mathrm{~A}$ \\
\hline Residue, $\mathrm{H}$ bond lengths & GLN 189, $2.185 \mathrm{~A}$ & & GLN $189,1.874 \mathrm{~A}$ & SER $158,2.424 \mathrm{~A}$ & & THR 49, $2.033 \mathrm{~A}$ \\
\hline Residue, $\mathrm{H}$ bond lengths & & & & ASP $153,2.111 \mathrm{~A}$ & & THR 49, 2.673 A \\
\hline
\end{tabular}

Details of biological activities of these candidate molecules and their structures, along with their $\log \mathrm{P}$ and $\log \mathrm{S}$ values (as determined from Drugbank website) are enlisted in table 3 . Log P is a prediction of the transport property of drugs and their interaction with receptors whereas $\log \mathrm{S}$ is an important indicator of drug solubility affecting its bioavailability. The log P values of these molecules were in the range of -0.91 (Methotrexate) to 4.39 (Vinorelbine), while Hydroxychloroquine had a log P of 3.87. Similarly, the log $S$ value of these molecules ranged between -3.4 and -4.8 . These $\log P$ and log $S$ values suggest that these drug molecules might diffuse readily across the cell membranes, as their lipid solubility value indicates so. Based on the binding affinities and combining the results of log P and 
$\log \mathrm{S}$ with the molecular docking analysis, it can be predicted that these four anticancer drugs

(Valrubicin, Vinorelbine, Methotrexate and Docetaxel) could be potential inhibitors of the COVID-19.

Table 3. Potential anticancer drugs as possible inhibitors for COVID-19, their properties and molecular structures, with lipophilicity and solubility details

\begin{tabular}{|c|c|c|c|c|c|c|}
\hline Drug & $\log P$ & $\log S$ & Drug type & Status & Indication, uses and properties & Structure \\
\hline Hydroxychloroquine & 3.87 & -4.1 & Small molecule & Approved & $\begin{array}{l}\text { Hydroxychloroquine is indicated for the prophylaxis } \\
\text { of malaria where chloroquine resistance is not } \\
\text { reported, treatment of uncomplicated malaria } \\
\text { (caused by } P \text {. falciparum, P. malariae, } P \text {. ovale, } \\
\text { or } P \text {. vivax ), chronic discoid lupus erythematosus, } \\
\text { systemic lupus erythematosus, acute rheumatoid } \\
\text { arthritis, and chronic rheumatoid arthritis. }\end{array}$ & \\
\hline Valrubicin & 2.67 & -4.4 & Small molecule & Approved & For the treatment of cancer of the bladder. & \\
\hline Vinorelbine & 4.39 & -4.8 & Small molecule & $\begin{array}{l}\text { Approved, } \\
\text { investigational }\end{array}$ & $\begin{array}{l}\text { Vinorelbine tartrate is indicated for adults in the } \\
\text { treatment of advanced non-small cell lung cancer } \\
\text { (NSCLC). For the treatment of recurrent or } \\
\text { metastatic squamous cell head and neck cancer. For } \\
\text { the treatment of recurrent ovarian cancer. }\end{array}$ & \\
\hline Methotrexate & -0.91 & -3.4 & Small molecule & Approved & $\begin{array}{l}\text { Methotrexate oral solution is indicated for pediatric } \\
\text { acute lymphoblastic leukemia and pediatric } \\
\text { polyarticular juvenile idiopathic arthritis. It is also } \\
\text { used in the maintenance of acute lymphocytic } \\
\text { leukemia. Methotrexate is also given before } \\
\text { treatment with leucovorin to prolong relapse-free } \\
\text { survival following surgical removal of a tumour in } \\
\text { non-metastatic osteosarcoma. }\end{array}$ & \\
\hline Docetaxel & 2.59 & -4.8 & Small molecule & Approved & $\begin{array}{l}\text { For the treatment of patients with locally advanced } \\
\text { or metastatic breast cancer after failure of prior } \\
\text { chemotherapy. Also used as a single agent in the } \\
\text { treatment of patients with locally advanced or } \\
\text { metastatic non-small cell lung cancer after failure of } \\
\text { prior platinum-based chemotherapy. Docetaxel has } \\
\text { uses in the treatment of gastric adenocarinoma and } \\
\text { head and neck cancer. }\end{array}$ & \\
\hline
\end{tabular}

Other molecules enlisted in table 1 , which had $\Delta \mathrm{G}$ score between -8.5 to -9.0 (font color-blue) will be analyzed later, in further studies. These molecules have a better $\Delta \mathrm{G}$ score as compared to current antiviral drugs that are being suggested as alternate remedies against COVID-19. Thus analysis with these suggested molecules in table 1 will be further accomplished. 


\section{Conclusion:}

This study was conducted to establish whether anticancer drugs used routinely as therapy, can be good molecules to inhibit COVID-19 using six different target proteins. This multi-targeted approach could be very useful strategy in the current situation since the virus is known to mutate rapidly. Drugs in this study are predicted to interact with more than four target proteins of COVID-19 with promising results. Although more computational analysis needs to be performed in order to confirm their potential. Wet lab validation of these molecules with COVID-19 will establish their efficacy as anti-COVID drugs.

\section{Acknowledgement:}

Author acknowledges help extended by Department of Biotechnology, Fergusson College (Autonomous), Pune. 


\section{References:}

1. Colson, P., Rolain, J. M., Lagier, J. C., Brouqui, P., \& Raoult, D. (2020). Chloroquine and hydroxychloroquine as available weapons to fight COVID-19. Int J Antimicrob Agents, 105932(10.1016).

2. Liu, X., \& Wang, X. J. (2020). Potential inhibitors against 2019-nCoV coronavirus M protease from clinically approved medicines. Journal of Genetics and Genomics.

3. Srivastava, A. K., Kumar, A., Tiwari, G., Kumar, R., \& Misra, N. (2020). In Silico Investigations on the Potential Inhibitors for COVID-19 Protease. arXiv preprint arXiv:2003.10642.

4. Dong, L., Hu, S., \& Gao, J. (2020). Discovering drugs to treat coronavirus disease 2019 (COVID19). Drug discoveries \& therapeutics, $14(1), 58-60$.

5. Jia, Yong, Gangxu Shen, Yujuan Zhang, Keng-Shiang Huang, Hsing-Ying Ho, Wei-Shio Hor, ChihHui Yang, Chengdao Li, and Wei-Lung Wang. "Analysis of the mutation dynamics of SARS-CoV-2 reveals the spread history and emergence of RBD mutant with lower ACE2 binding affinity." bioRxiv (2020).

6. Roner, M. R., Carraher, C. E., Dhanji, S., \& Barot, G. (2008). Antiviral and anticancer activity of cisplatin derivatives of tilorone. Journal of Inorganic and Organometallic Polymers and Materials, 18(3), 374.

7. Bekerman, E., Neveu, G., Shulla, A., Brannan, J., Pu, S.Y., Wang, S., Xiao, F., Barouch-Bentov, R., Bakken, R.R., Mateo, R. and Govero, J., 2017. Anticancer kinase inhibitors impair intracellular viral trafficking and exert broad-spectrum antiviral effects. The Journal of clinical investigation, 127(4), pp.1338-1352. 
8. Joshi, R., S. Jagdale, S. Bansode, S. S. Shankar, M. Tellis, V. K. Pandya, A. Giri, and M. Kulkarni. "Discovery of Multi-Target-Directed Ligands by Targeting Host-specific SARS-CoV-2's Structurally Conserved Main Protease." (2020).

9. Yoshino, R., Yasuo, N., \& Sekijima, M. (2020). Identification of key interactions between SARSCoV-2 Main Protease and inhibitor drug candidates.

10. Du, L., He, Y., Zhou, Y., Liu, S., Zheng, B. J., \& Jiang, S. (2009). The spike protein of SARS-CoV-a target for vaccine and therapeutic development. Nature Reviews Microbiology, 7(3), 226-236.

11. Abbasi, A. M., Ayaz, Z., \& Zainab, B. (2020). In silico elucidation revealed SARS CoV and MERS CoV Drug Compounds could be Potential Therapeutic Candidates against Post Fusion Core (S2) Protein of Novel Coronavirus (2019-nCov).

12. Joshi, G., \& Poduri, R. (2020). Virtual screening enabled selection of antiviral agents against Covid-19 disease targeting coronavirus endoribonuclease NendoU: Plausible mechanistic interventions in the treatment of new virus strain.

13. Grosdidier, A., Zoete, V., \& Michielin, O. (2011). SwissDock, a protein-small molecule docking web service based on EADock DSS. Nucleic acids research, 39(suppl_2), W270-W277.

14. Pettersen, E. F., Goddard, T. D., Huang, C. C., Couch, G. S., Greenblatt, D. M., Meng, E. C., \& Ferrin, T. E. (2004). UCSF Chimera-a visualization system for exploratory research and analysis. Journal of computational chemistry, 25(13), 1605-1612. 